\title{
Highly conserved genes in Geobacter species with expression patterns indicative of acetate limitation
}

\author{
Correspondence \\ Carla Risso \\ crisso@microbio.umass.edu
}

Received 1 February 2008

Revised 23 May 2008

Accepted 4 June 2008

\author{
Carla Risso, ${ }^{1}$ Barbara A. Methé, ${ }^{2}$ Hila Elifantz, ${ }^{1}$ Dawn E. Holmes ${ }^{1}$ \\ and Derek R. Lovley ${ }^{1}$
}

\author{
${ }^{1}$ Department of Microbiology, 203N Morrill Science Center IVN, University of Massachusetts \\ Amherst, Amherst, MA 01003, USA
}

2J. Craig Venter Institute, 9712 Medical Center Drive, Rockville, MD 20850, USA

\section{INTRODUCTION}

Rational design of groundwater bioremediation strategies requires information on the in situ physiological status of the micro-organisms in the subsurface (Lovley, 2003; Lovley et al., 2008). Such knowledge will make it possible to tailor amendments to groundwater to optimize bioremediation processes of interest. For example, the addition of electron donors, such as acetate, to stimulate dissimilatory metal reduction has proven to be an effective strategy for promoting the reductive precipitation of toxic metals, thereby immobilizing them and preventing their further migration through the subsurface. In the case of uranium, soluble $\mathrm{U}(\mathrm{VI})$ is microbially reduced to insoluble U(IV) (Amos et al., 2007; Anderson et al., 2003; Cummings

Abbreviation: qRT-PCR, quantitative real-time polymerase chain reaction.

A supplementary table of the primers used for qRT-PCR is available with the online version of this paper. et al., 2003; Istok et al., 2004; Luo et al., 2007; N'Guessan et al., 2008; North et al., 2004; Petrie et al., 2003; Sanford et al., 2007; Vrionis et al., 2005). In most instances, Geobacter species have been identified as the primary $\mathrm{U}(\mathrm{VI})$-reducing micro-organisms during active uranium precipitation (Anderson et al., 2003; Holmes et al., 2002, 2007; Sanford et al., 2007). While in some cases adding limiting nutrients to optimize maximum growth rates is the preferred option, in other instances it may actually be preferable to design strategies in which rates of metabolism are regulated to suit particular needs. During most initial field trials on acetate-driven in situ uranium bioremediation, relatively high concentrations of electron donor were added to stimulate rapid growth of Geobacter species. However, rapid growth of Geobacter species is associated with rapid depletion of $\mathrm{Fe}(\mathrm{III})$ oxides, the primary electron acceptor for growth of Geobacter species in uraniumcontaminated subsurface sediments (Finneran et al., 2002; Holmes et al., 2002, 2004a). As Fe(III) oxides are depleted, 
sulfate-reducing micro-organisms that are less effective $\mathrm{U}(\mathrm{VI})$ reducers than Geobacter species become prevalent. Therefore, it may be more desirable to fine tune acetate additions so that the growth of Geobacter species and $\mathrm{U}(\mathrm{VI})$ reduction are stimulated, yet remain acetate-limited, thereby slowing the depletion of $\mathrm{Fe}(\mathrm{III})$ oxides.

Insights into some aspects of the in situ physiological status of Geobacter species in subsurface environments have been derived from analysis of transcript levels for key genes (Holmes et al., 2004a, b, 2005). High levels of nifD transcripts suggested that Geobacter species were limited for fixed nitrogen in aquifer sediments, and fixed atmospheric nitrogen (Holmes et al., 2004b). Transcript levels for genes involved in central metabolism were related to rates of metabolism in the subsurface (Holmes et al., 2005). In addition, differential expression of two genes encoding multi-copper containing proteins was related to differences in growth rates in the subsurface (Mehta et al., 2006). In each case, studies of gene expression in the environment were preceded by genome-scale analysis of the metabolic processes of interest in pure cultures, with the primary focus on Geobacter sulfurreducens because of the availability of a complete genome sequence (Methé et al., 2003), a genetic system (Coppi et al., 2001; Lloyd et al., 2003), and a genome-scale metabolic model (Mahadevan et al., 2006).

We hypothesized that levels of expression of genes for acetate transporters in Geobacter species might be indicative of the availability of acetate to these organisms. To our knowledge, the only acetate transport system described to date is Escherichia coli ActP, a membrane permease highly specific for short-chain aliphatic monocarboxylates, which belongs to the sodium-solute symporter family (Gimenez et al., 2003). The expression of the operon that includes the actP gene was upregulated in acetate-grown versus glucose-grown E. coli (Oh et al., 2002). Here we report that genes with high homology to actP are highly conserved in the genomes of cultured Geobacter species as well as in uncultured Geobacter species that predominate during in situ uranium bioremediation. In addition, these genes are highly expressed in acetate-limited Geobacter sulfurreducens in continuous cultures. These characteristics make these transporter genes uniquely suited to act as phylogenetic and physiological markers of Geobacterdominated communities in acetate-driven bioremediation processes.

\section{METHODS}

Bacterial strains and culturing conditions. Geobacter sulfurreducens strain DL1 (ATCC 51573) (Coppi et al., 2001) was obtained from our laboratory culture collection and used to construct strains DLCR1 (aplB::kn), DLCR2 (aplA::kn) and DLCR3 (aplC::kn) as described below. Strains were cultured under strict anaerobic conditions at $30{ }^{\circ} \mathrm{C}$ in a $\mathrm{N}_{2} / \mathrm{CO}_{2}(80 \%: 20 \%)$ atmosphere as previously described (Caccavo et al., 1994) in either freshwater medium (Lovley \& Phillips, 1988) or NBAF medium (Coppi et al., 2001). When noted, kanamycin was added at $50 \mu \mathrm{g} \mathrm{ml}{ }^{-1}$. For the growth curves, freshwater medium containing $10 \mathrm{mM}$ acetate and $56 \mathrm{mM}$ ferric citrate was used. Continuous culture was carried out in freshwater medium as previously described (Esteve-Nuñez et al., 2005) in acetate-limiting conditions ( $5 \mathrm{mM}$ acetate, $30 \mathrm{mM}$ fumarate) or fumarate-limiting conditions ( $10 \mathrm{mM}$ acetate, $10 \mathrm{mM}$ fumarate). The dilution rate was $0.05 \mathrm{~h}^{-1}$.

Determination of acetate consumption in resting cell suspensions. Cell suspensions were prepared by harvesting $800 \mathrm{ml}$ of lateexponential-phase cultures of DL1 and DLCR3 grown in freshwater medium ( $20 \mathrm{mM}$ acetate, $56 \mathrm{mM}$ ferric citrate). All manipulations were performed in an anaerobic chamber. The cultures were centrifuged at $4300 \mathrm{~g}$ at $4{ }^{\circ} \mathrm{C}$, washed with anoxic isotonic basal wash medium (BWM) (Leang et al., 2003) and resuspended in pressure tubes with $\mathrm{BWM}$ to $\mathrm{OD}_{600}=2$. The tubes were placed at $30{ }^{\circ} \mathrm{C}$ and amended with $10 \mathrm{ml}$ of hydrogen and $30 \mathrm{mM}$ ferric citrate. The reactions were started by the addition of $2 \mathrm{mM}$ acetate. Aliquots were taken at appropriate times, filtered and diluted. Acetate concentration was determined by HPLC. The results were normalized to the total protein concentration of the cell suspension.

Construction of acetate-permease-like (ap/) mutants via single-step gene replacement. Single-step gene replacement was performed as previously described (Coppi et al., 2001; Lloyd et al., 2003). The sequences of all primers used for the construction and screening of strains DLCR1, DLCR2 and DLCR3 are listed in Table 1. To create a linear DNA fragment for the construction of mutant DLCR1 $(a p l B:: k n)$ three primary fragments were generated independently by PCR. The first fragment was amplified from DL1 chromosomal DNA using primers 1070-1 and 1070-2. The middle fragment containing a kanamycin-resistance cassette was amplified from plasmid pBBR1MCS-2 (Kovach et al., 1995) with hybrid primers $1070-3 \mathrm{Kn}$ and $1070-4 \mathrm{Kn}$. The third fragment was amplified from DL1 chromosomal DNA using primers 1070-5 and 1070-6. PCR conditions were as follows: 5 cycles at $95{ }^{\circ} \mathrm{C}, 30 \mathrm{~s} ; 50{ }^{\circ} \mathrm{C}, 45 \mathrm{~s} ; 72{ }^{\circ} \mathrm{C}$, $1 \mathrm{~min}$; followed by 30 additional cycles at $95{ }^{\circ} \mathrm{C}, 30 \mathrm{~s} ; 62{ }^{\circ} \mathrm{C}, 45 \mathrm{~s}$; $72{ }^{\circ} \mathrm{C}, 1 \mathrm{~min}$. All reactions were preceded by a $5 \mathrm{~min}$ incubation at $95{ }^{\circ} \mathrm{C}$ during which the Taq polymerase was added ('hot start') and followed by a $10 \mathrm{~min}$ extension period at $72{ }^{\circ} \mathrm{C}$. The amplified fragments were gel-purified and joined by recombinant PCR. The resulting linear fragment was amplified with distal primers 1070-1 and 1070-6. PCR conditions during these two steps were as described above except that an extension time of $3 \mathrm{~min}$ at $72{ }^{\circ} \mathrm{C}$ was employed. A similar strategy was employed to make the other two mutants. For construction of DLCR2 (aplA::kn), the first fragment was amplified from DL1 chromosomal DNA using primers 1068-1 and 1068-2; the middle segment containing a kanamycin-resistance cassette was amplified from plasmid pBBR1MCS-2 (Kovach et al., 1995) with hybrid primers $1068-3 \mathrm{Kn}$ and $1068-4 \mathrm{Kn}$; and the third fragment was amplified from DL1 chromosomal DNA with primers 1068-5 and 1068-6. For construction of DLCR3 ( aplC::kn), the first fragment was amplified from DL1 chromosomal DNA using primers 2352-1 and 2352-2; the middle segment containing a kanamycin-resistance cassette was amplified from plasmid pBBR1MCS-2 (Kovach et al., 1995 ) with hybrid primers $2352-3 \mathrm{Kn}$ and $2352-4 \mathrm{Kn}$; and the third fragment was amplified from DL1 chromosomal DNA with primers 2352-5 and 2352-6.

For the construction of aplB-aplA and aplB-aplC double mutants, hybrid primers $1068-3 \mathrm{Kn}$ and $1068-4 \mathrm{Kn}$ were modified to amplify a gentamicin-resistance cassette, and $2352-3 \mathrm{Kn}$ and $2352-4 \mathrm{Kn}$ were modified to amplify a chloramphenicol-resistance cassette (sequences not shown). Linear recombinant DNA fragments were constructed as described above and used to transform DLCR1 (aplB:: $k n$ mutant) and DL1 competent cells. Similarly, linear fragments containing the aplB:: $k n$ or $a p l C:: \mathrm{cm}$ constructs were used to transform DL1 and 
Table 1. Oligonucleotides used in this work

\begin{tabular}{|c|c|c|}
\hline Oligonucleotide & Coordinates $* /$ use & Sequence $\left(5^{\prime}-3^{\prime}\right)$ \\
\hline $1068-1$ & 1163503 & GCAACATTGCCATTTACAGC \\
\hline $1068-2$ & 1164006 & CATCGGGTTCATTCCTCCTT \\
\hline $1068-4 \mathrm{Kn}$ & Hybrid primer & GACCTTCCCCCAGAGTGTAACATCGCTTGGTCGGTCATTTC \\
\hline $1068-5$ & 1166017 & GTTACACTCTGGGGGAAGGTC \\
\hline $1068-6$ & 1166521 & CGTCCCCATAAACAATCAGG \\
\hline $1070-2$ & 1161101 & CACAGACCTCСТTCCTATTTG \\
\hline $1070-3 \mathrm{Kn}$ & Hybrid primer & CAAATAGGAAGGAGGTCTGTGAGCTACTGGGCTATCTGGACAA \\
\hline $1070-4 \mathrm{Kn}$ & Hybrid primer & CAAACGAGGGTATGAAACAGATCGCTTGGTCGGTCATTTC \\
\hline $1070-5$ & 1163161 & CTGTTTCATACCCTCGTTTG \\
\hline $1070-6$ & 1164003 & CGGGTTCATTCCTCCTTAC \\
\hline $2352-1$ & 2573415 & GTGCCATCGTTCAGGGCTGTG \\
\hline $2352-5$ & 2575991 & TATGTGACAGGAGGGGGTAGC \\
\hline $2352-6$ & 2576516 & CTATCCTGACCATCGCCTACG \\
\hline 2352-Rchk & 2576491 & CACGAAAGTGGATAACAGGC \\
\hline $\mathrm{KnF}$ & Confirm aplC mutant genotype & ATTGCACGCAGGTTCTCC \\
\hline $422 \mathrm{Fw}$ & Degenerate primer & TSTCSGCNGCCWCNTTCCT \\
\hline $660 \mathrm{Rv}$ & Degenerate primer & TTNCCBGCVCCNCCATCTG \\
\hline
\end{tabular}

${ }^{\star}$ Coordinates refer to the $5^{\prime}$ end in the G. sulfurreducens genome.

aplA:: gm mutants. Hybrid primers $1068-3 \mathrm{Kn}$ and $1070-4 \mathrm{Kn}$ were used to construct a recombinant fragment to replace the whole GSU1068-GSU1070 region.

Electroporation and mutant isolation were carried out as previously described (Coppi et al., 2001; Lloyd et al., 2003) except that the recovery medium and plates were supplemented with $10 \mathrm{mM}$ pyruvate and $\mathrm{H}_{2}$. One colony of each of the mutants was selected as representative for further analysis. In order to confirm their genotypes, the mutant and wild-type strains were screened with combinations of primers which annealed outside and inside the mutagenic constructs and thus were expected to yield amplicons only in specific mutants. Primers 1070-1/1070-4Kn and 1070-3Kn/1070-6 were used to confirm the presence of the aplB:: $k n$ mutation in strain DLCR1. Primers 1068-1/1068-4Kn and 1068-3Kn/1068-6 were used to confirm the presence of the aplA:: $k n$ mutation in strain DLCR2. Primers KnF and 2532R-chk were employed to confirm the aplC mutation in strain DLCR3. As expected, bands of the correct sizes were obtained from all the mutants, but not from the wild-type (not shown).

Analytical techniques. Growth of fumarate cultures was assessed by measuring $\mathrm{OD}_{600}$ in pressure tubes $(1.5 \mathrm{~cm}$ path) with a Genesys 2 spectrophotometer (Spectronic Instruments). Fe(II) concentration was determined with the ferrozine assay as previously described (Lovley \& Phillips, 1986). Protein concentrations were determined by the bicinchoninic acid method with BSA as standard (Smith et al., 1985). The organic acid content of the medium in the resting cell suspension experiment was determined by HPLC using an LC-10AT high-pressure liquid chromatograph (Shimadzu) equipped with an Aminex HPX-87H column $(300 \times 7.8 \mathrm{~mm}$; Bio-Rad $)$. Organic acids were eluted in $8 \mathrm{mM} \mathrm{H}_{2} \mathrm{SO}_{4}$ and quantified with an SPD-10VP UV detector (Shimadzu) set at $215 \mathrm{~nm}$.
Nucleic acid manipulations. Genomic DNA preparations, RNA extractions and gel extractions were carried out using Qiagen Genome-tip 100G, RNeasy Mini and Qiaquick Gel Extraction kits respectively.

Quantitative real-time PCR (qRT-PCR). Cells from steady-state chemostats were harvested by centrifugation and pooled for RNA extraction. Total RNA was extracted as described above. A reverse transcription reaction was performed to synthesize single-stranded cDNA from approximately $1 \mu \mathrm{g}$ total RNA from each sample in a $100 \mu \mathrm{l}$ reaction volume using Taqman Reverse Transcription Reagents (Applied Biosystems). Reactions were performed in duplicate for each gene tested. The resulting cDNA was subsequently used as template for real-time PCR using the SYBR Green PCR Master Mix (Applied Biosystems) and primers suitable for qRT-PCR amplification that were designed using Primer3 (Rozen \& Skaletsky, 2000) software. These gene-specific primers are listed in Supplementary Table S1, available with the online version of this paper. Forward and reverse primers were added to the reaction at a final concentration of $200 \mathrm{nM}$ along with $1 \mu \mathrm{l}$ of the cDNA reaction. The incorporation of SYBR Green dye into the PCR products was detected in real time on the ABI Prism 7900HT Sequence Detection System. Relative expression levels were calculated by the $2^{-\Delta \Delta C t}$ method (Livak \& Schmittgen, 2001). Values of approximately 1 reflect little or no significant change in expression.

Phylogenetic analysis of acetate permease-like proteins from sequenced genomes. The amino acid sequences of the sodiumsolute symporters were aligned with CLUSTAL_X software (Thompson et al., 1997). Aligned sequences were imported into PAUP $4.0 \mathrm{~b} 10$ to construct the phylogenetic tree (Swofford, 1998). Distances were determined using distance-based algorithms (neighbour-joining) (Saitou \& Nei, 1987). Bootstrap values were obtained from 100 
replicates. Preliminary sequence data from Geobacter metallireducens, G. uraniireducens, G. bemidjiensis, G. lovleyi and FRC-32 were obtained from the DOE JGI website (http://www.jgi.doe.gov).

Design of degenerate primers for detection of Geobacter Group I apl genes in environmental samples. Nucleotide sequences of Group I apl genes from all available Geobacter genomes were aligned. Conserved regions were identified and used to design a pair of degenerate primers, $422 \mathrm{Fw}$ and $660 \mathrm{Rv}$ (Table 1), that produced a $222 \mathrm{bp}$ amplicon. To verify that these primers targeted the Group I apl genes of the Geobacter species, they were tested using genomic DNA from G. sulfurreducens, G. metallireducens, G. uraniireducens, G. bemidjiensis and G. lovleyi as templates. The PCR conditions used were: $95{ }^{\circ} \mathrm{C}, 3 \mathrm{~min},\left(95^{\circ} \mathrm{C}, 30 \mathrm{~s} ; 60{ }^{\circ} \mathrm{C}, 45 \mathrm{~s} ; 72{ }^{\circ} \mathrm{C}\right.$, $90 \mathrm{~s}), 30$ cycles; $72{ }^{\circ} \mathrm{C}, 10 \mathrm{~min}$ - except for G. bemidjiensis, where annealing temperature was $54^{\circ} \mathrm{C}$.

Environmental DNA sampling and extraction. The sample analysed was collected from groundwater extracted from well M21 of a uranium-contaminated aquifer undergoing acetate-stimulated bioremediation in Rifle, Colorado, USA (Holmes et al., 2005). The sample corresponds to the M21 well of the 2005 study, on the 14th day of sampling, when the Geobacter content of the microbial community was $80 \%$ (Holmes et al., 2007). Cells were collected from groundwater using Sterivex filters (Millipore). Following cell collection, the filters were flash-frozen in a dry-ice/ethanol bath, shipped back to the laboratory at $-20{ }^{\circ} \mathrm{C}$ and stored at $-80{ }^{\circ} \mathrm{C}$ for further use. DNA was extracted from half of the filter using Bio 101 FastDNA soil kits (MP Biomedicals).

Clone library construction and diversity analysis. The acetate permease-like gene fragment was amplified from environmental DNA from well M21 using the degenerate primers and PCR conditions described above. The PCR products were subjected to electrophoresis on a $2 \%$ agarose gel and the $222 \mathrm{bp}$ amplicon was excised and purified. The purified PCR products were cloned using the TOPO TA cloning kit (Invitrogen) according to the manufacturer's instructions. Ninety-six clones were picked and sequenced with the M13F and M13R primers at the University of Massachusetts Sequencing Facility. Neighbour-joining phylogenetic trees of nucleotide acid sequences with bootstrap values based on 100 replicates were constructed with MEGA 3 (Kumar et al., 2004). Rarefaction curves for determination of diversity coverage were calculated using DOTUR software (Schloss \& Handelsman, 2005) (not shown). The 16S rRNA genes were amplified from environmental DNA with primers 8F (Eden et al., 1991) and 519R (Lane et al., 1985).

\section{RESULTS AND DISCUSSION}

\section{Homologues of an E. coli acetate transporter in Geobacter species}

Protein BLAST analysis revealed four homologues of the $E$. coli acetate permease, ActP, in the G. sulfurreducens genome. GSU1068, GSU1070, GSU2352 and GSU0518 were designated AplA, AplB, AplC and AplD, respectively, for acetate permease-like, and had previously been annotated as a sodium-solute symporter (Methé et al., 2003). Three of these, AplA, AplB and AplC, were highly similar to each other, with over $90 \%$ identity at the amino acid level, and also shared $46 \%$ identity with ActP of E. coli. The three homologues are 659 aa proteins with 13 predicted transmembrane segments and a signal peptide; their predicted molecular mass is $\sim 61 \mathrm{kDa}$ (http:// cmr.tigr.org/tigr-scripts/CMR/GenomePage.cgi?org=ggs). The physical arrangement of each of these genes in the chromosome suggests that each is in a two-gene operon that also contains an ORF encoding a conserved hypothetical protein (GSU1069, GSU1071 and GSU2353) (Fig. 1). Predicted promoter and terminator structures are located immediately upstream of the conserved hypothetical protein and downstream of the putative transporter sequences respectively. AplD is a less similar fourth paralogue, with an average $24 \%$ identity to AplA, AplB and AplC and $30 \%$ identity to ActP. It constitutes a 508 aa protein, also with 13 predicted transmembrane segments. Its chromosomal arrangement differs from its counterparts; its preceding hypothetical protein, GSU0519, does not share homology with GSU1069, GSU1071 or GSU2353. Furthermore, the ORFs corresponding to GSU0518 and GSU0519 overlap by $7 \mathrm{bp}$ (Fig. 1).

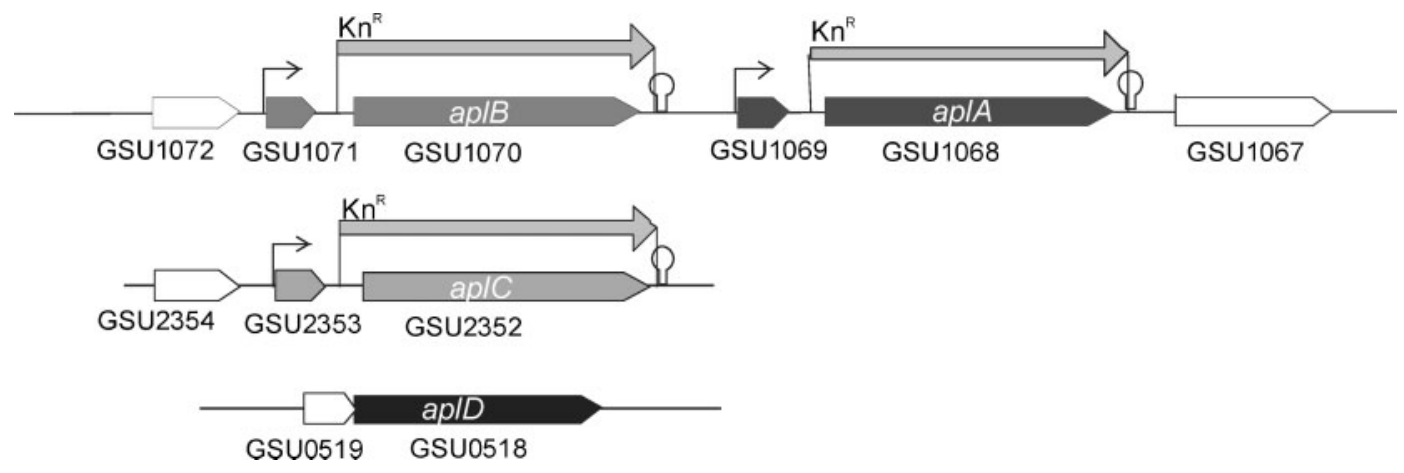

Fig. 1. Physical arrangement of ap/ genes in the genome of G. sulfurreducens. Upper bars represent the deleted portions of the genome that were replaced by a kanamycin-resistance cassette in each of the three single mutants. Note that the coding sequences of GSU0518 and GSU0519 overlap by $7 \mathrm{bp}$. Operons, promoters and terminators were predicted using the commercial version of the FGENES-B software package (Softberry Inc.) as previously described (Yan et al., 2004). 


\section{Phylogenetic analysis of Apl proteins in the family Geobacteraceae and other acetate-oxidizing bacteria}

Putative acetate transporter homologues are widely conserved among acetate-oxidizing bacteria. Phylogenetic analysis indicated that these proteins can be divided into two distinct clades designated Group I and Group II (Fig. 2). It is worth noting that all members of the genus Geobacter whose genomes have been sequenced possess multiple Group I Apl homologues and a single Group II Apl homologue, including G. metallireducens, G. lovleyi, G. uraniireducens, G. bemidjiensis and Geobacter strain
FRC-32. In the case of G. sulfurreducens, AplA, AplB and AplC belong to Group I, while AplD belongs to Group II. All Geobacter Group I Apl sequences cluster in a tight, wellsupported clade, with identities at or above $62 \%$ and similarities at or above $79 \%$. Apl sequences from Geobacter spp. are more closely related to those of Firmicutes than they are to Apl sequences of other Proteobacteria, such as Rhodoferax ferrireducens (Betaproteobacteria) or Escherichia coli (Gammaproteobacteria).

Group II also contains a separate Geobacter clade that includes the single Apl homologue from Desulfuromonas acetoxidans, a marine $\mathrm{Fe}(\mathrm{III})$-reducing and acetate-oxidizing

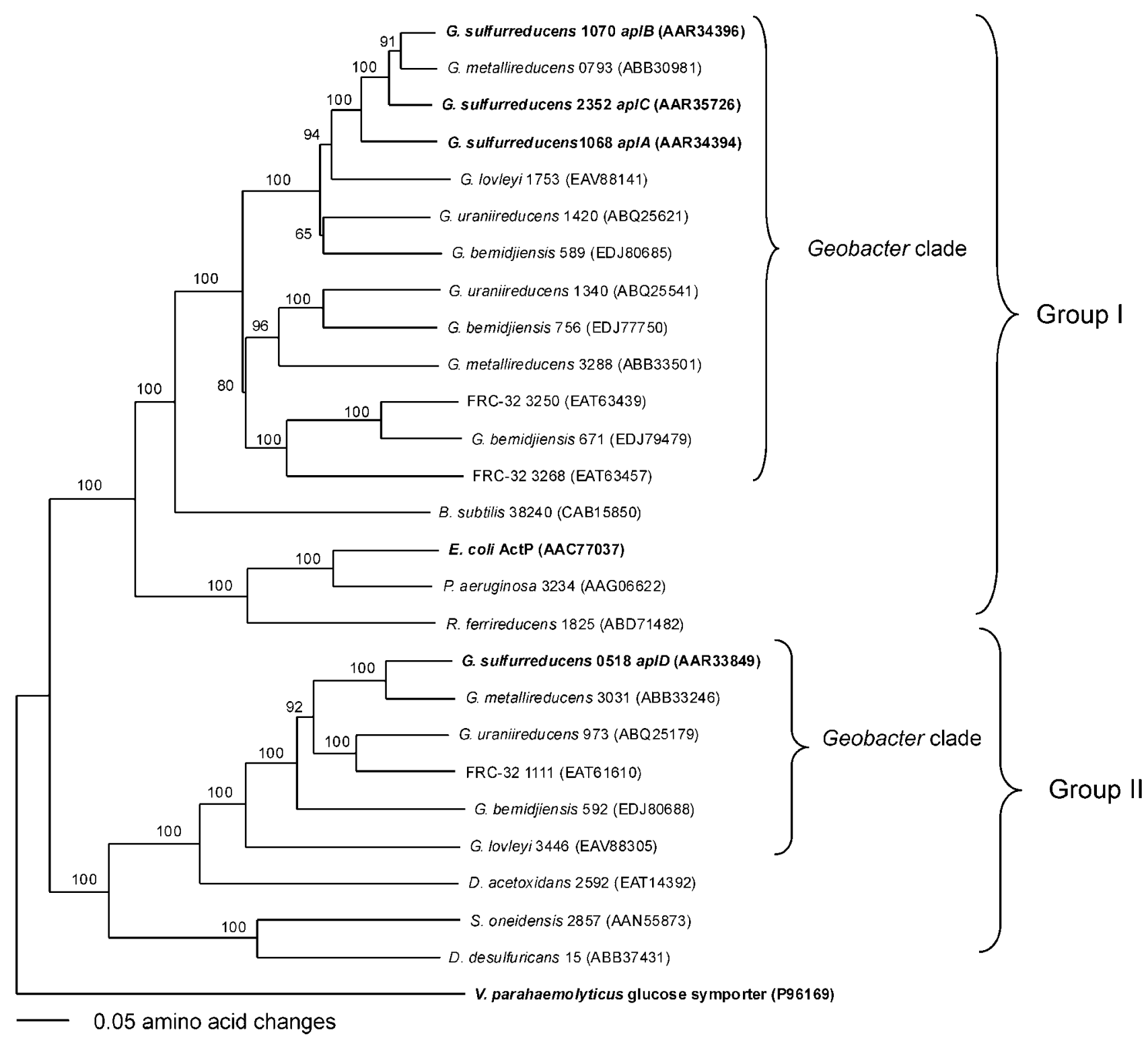

Fig. 2. Phylogenetic analysis of sodium-solute symporters from Geobacteraceae and other acetate-oxidizing organisms. The phylogenetic tree was inferred from protein sequences by neighbour-joining (Saitou \& Nei, 1987) with bootstrap values based on 100 replicates. The glucose symporter from $V$. parahaemolyticus was used as an outgroup. The characterized acetate transporter of E. coli, ActP, and ap/ genes from G. sulfurreducens are indicated in bold type. 
member of the family Geobacteraceae. Other members from the Deltaproteobacteria (Desulfovibrio vulgaris) and Gammaproteobacteria (Shewanella oneidensis) possess putative acetate transporter homologues from Group II. Notably, no Apl homologues were found in Pelobacter species. These organisms are phylogenetically intertwined with acetateoxidizing Geobacteraceae, but are unable to use acetate as an electron donor (Haveman et al., 2006; Lovley et al., 1995; Schink, 1984).

\section{Expression in response to acetate limitation}

In order to determine whether acetate limitation affected the expression of the apl genes, the ratio of transcript levels was quantified in continuous cultures of G. sulfurreducens grown under electron-donor-limiting or electron-acceptor limiting conditions (acetate and fumarate, respectively) by qRT-PCR. The expression of the Group I genes, aplA, aplB and $a p l C$, was 6-9-fold higher under acetate-limiting conditions relative to fumarate-limiting conditions (Fig. 3). The transcript levels of each of the small conserved hypothetical proteins upstream each of the apl genes (GSU1069, GSU1071 and GSU2353) were also higher under acetate-limited conditions, consistent with the predicted operon structure. In contrast, transcript levels for flanking genes that were not predicted to be within the same operons (GSU1067, GSU1072 and GSU2354) were similar under both growth conditions (Fig. 3). Transcript levels for the Group II transporter, aplD, were not affected by either acetate or fumarate limitation.

These results were in agreement with microarray analyses of electron-donor-limiting versus electron-acceptorlimiting conditions. In G. sulfurreducens, transcription of the three members of Group I was upregulated under acetate-limited conditions, while the single member from Group II displayed no change in expression (A. EsteveNuñez, unpublished). In G. metallireducens, transcription of Gmet793, a closely related homologue of Group I with identities to GSU1068, GSU1070 and GSU2352 ranging from $89 \%$ to $94 \%$ (Fig. 2), was upregulated in acetatelimiting conditions. Transcription of Gmet3031, which belongs to Group II, was not affected (Didonato et al., 2006). These results suggest that high levels of expression of Group I genes are indicative of acetate limitation, which is also consistent with their proposed role as acetate transporters. The lack of increased expression of Group II genes does not necessarily rule out a role in acetate transport, as constitutive expression of one of multiple acetate transporters might not be maladaptive.

\section{Effect of gene deletion}

Because of their apparent role in acetate uptake, the potential function of the Group I apl genes was further characterized by genetic analysis. Single mutants in which $a p l A$, aplB or $a p l C$ was deleted were constructed by replacing each gene with a kanamycin-resistance cassette (Fig. 1). The acetate recovery and selection medium included an alternative electron donor (hydrogen) and carbon source (10 mM pyruvate) in order to enable growth should the mutant be incapable of uptaking acetate.

All the strains with a single mutation grew as well as the wild-type in a medium in which acetate was the electron donor and fumarate was the electron acceptor (Fig. 4a). When ferric citrate was used as electron acceptor, aplA and $a p l B$ mutants reduced $\mathrm{Fe}(\mathrm{III})$ at the same rate as the wildtype. The aplC mutant exhibited a diminished rate of $\mathrm{Fe}$ (III) reduction (Fig. 4b), but the biomass yield was similar to the wild-type $\left(21.9 \pm 0.7 \mathrm{mg}\right.$ total protein $\left.\mathrm{l}^{-1}\right)$. In all strains, the acetate consumption profile during growth on ferric citrate matched the growth rate (Fig. 4c). The slow-growth phenotype of the aplC mutant during growth on ferric citrate was studied by measuring the acetate consumption of this mutant and the wild-type

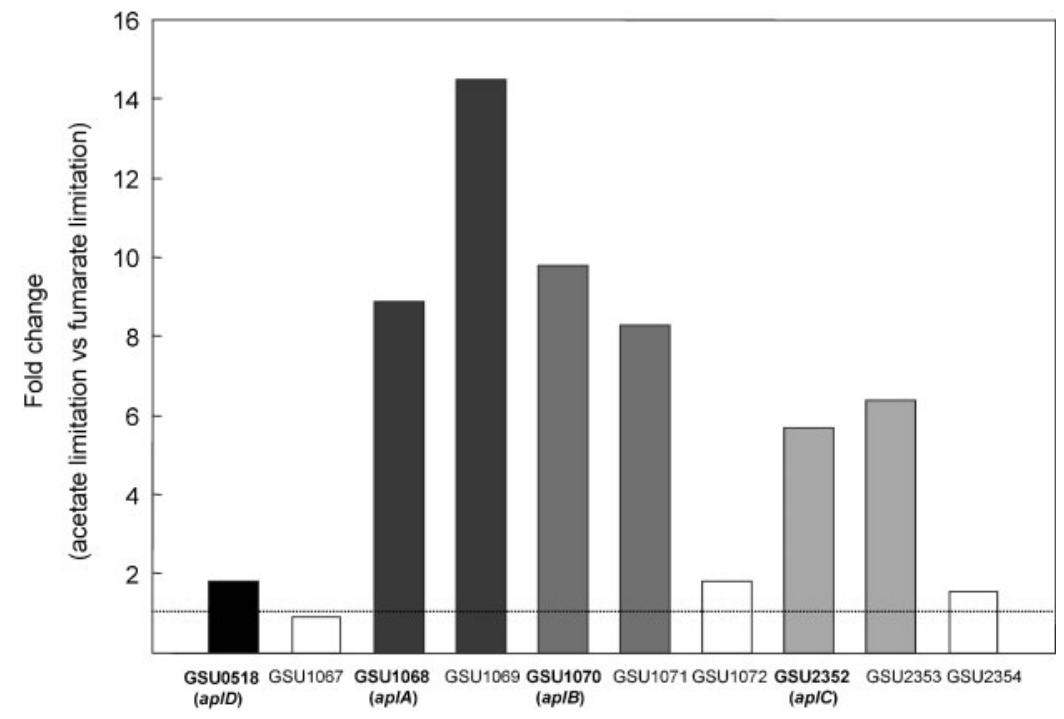

Fig. 3. Upregulation of $G$. sulfurreducens Group I apl genes under acetate-limiting conditions. qRT-PCR was performed with the SYBR Green PCR Master kit (Applied Biosystems). Relative expression ratios (limiting acetate versus limiting fumarate) were statistically analysed by the $2^{-\Delta \Delta C t}$ method (Livak \& Schmittgen, 2001). The shading of the bars corresponds to that used in Fig. 1. 



Fig. 4. (a) Growth of wild-type (DL1) and ap/ mutant strains in $20 \mathrm{mM}$ acetate with $40 \mathrm{mM}$ fumarate as electron acceptor (NBAF medium); (b) Fe(III) reduction of wild-type and ap/ mutants in $5 \mathrm{mM}$ acetate, $56 \mathrm{mM}$ ferric citrate (freshwater medium). Inocula (5\%) were exponential-phase acetate : fumarate cultures in both cases. Each determination represents the mean \pm SD of triplicate cultures (error bars not shown where smaller than symbols). (c) Acetate concentration in freshwater medium during growth of wild-type and mutant strains in Fe(III) citrate. (d) Acetate consumption in resting cell suspensions of wild-type (DL1) and the ap/C mutant prepared from cells grown in freshwater medium with $20 \mathrm{mM}$ acetate and $56 \mathrm{mM} \mathrm{Fe}(\mathrm{III})$ citrate.

strain in resting cell suspensions, i.e. in growth-independent conditions with ferric citrate as electron acceptor. Interestingly, the rate of acetate consumption by the aplC mutant was comparable to that of the wild-type under these conditions (Fig. 4d). This indicates that the effect of the aplC mutation during growth on ferric citrate may not have been directly related to acetate uptake and thus it was not further investigated.

Given the high degree of similarity among the Group I apl genes, the fact that single mutants in these genes are not impaired in growth via acetate may be due to functional redundancy. In order to investigate this possibility, the mRNA levels of the remaining apl genes were measured in each of the single mutants and compared to those of the wild-type (Fig. 5). In the case of the aplB mutant, the expression of aplA was upregulated. Conversely, aplB was upregulated in the aplA mutant. In both cases, the levels of $a p l C$ and $a p l D$ remained constant. In the case of the $a p l C$ mutant, only aplB was upregulated. These data suggest that compensatory changes in apl expression occur in $G$. sulfurreducens.

The construction of double knockouts of Group I genes using different antibiotic markers for each apl gene was attempted in order to isolate and study the function of single apl genes. However, the introduction of aplA::gm or

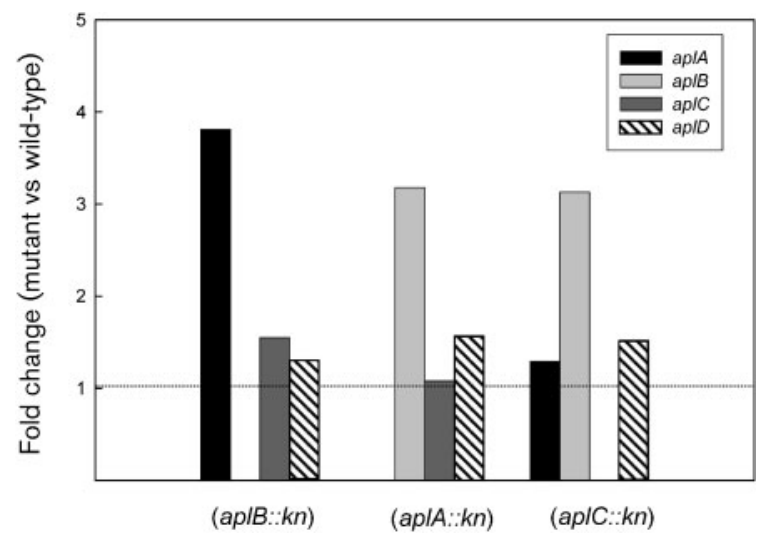

Fig. 5. Ratio of ap/ transcript levels in three Group I ap/ single mutants relative to wild-type. qRT-PCR was performed with the SYBR Green PCR Master kit (Applied Biosystems). Relative expression ratios (wild-type versus mutant) were statistically analysed by the $2^{-\Delta \Delta C t}$ method (Livak \& Schmittgen, 2001). 
aplC:: $\mathrm{cm}$ alleles was successful in DL1, but not in aplB:: $k n$ mutants (DLCR1). Similarly, introduction of aplC:: $\mathrm{cm}$ and aplB::kn markers in aplA::gm mutants failed as well. It is worth mentioning here that the sequential introduction of antibiotic-marked mutations in G. sulfurreducens has been successful in other studies (Risso et al., 2008; Segura et al., 2008). To attempt to overcome this problem we tried a different strategy whereby the whole chromosomal region comprising aplA and $a p l B$ was replaced with a single antibiotic marker via a single step as previously described (Kim et al., 2006). However, this effort also proved ineffective. This suggests that at least two of these three transporter genes are required to support growth.

Complementation of an E. coli strain lacking the ActP protein could not be accomplished because the cloned Group I members could not be functionally expressed (data not shown).

Thus, although the sequence similarity to the known acetate transporter in E. coli and the increased expression of the Group I transporter genes under acetate-limiting conditions suggest that these genes might be involved in acetate transport, it has not yet been possible to definitively prove this with a genetic approach. Similar difficulties were encountered during the study of $\sigma^{54}$, which could not be knocked out and was subsequently determined to be an essential gene (C. Leang, unpublished).

\section{Detection of ap/ genes in a field sample collected during in situ acetate-mediated uranium bioremediation}

Group I apl genes represent valid phylogenetic and physiological biomarkers due to their high degree of conservation among Geobacter species and their increased transcription in response to acetate limitation (Figs 2 and 3). Monitoring the expression of these genes may be an effective strategy for determining when acetate availability is limiting the growth and activity of Geobacter species in subsurface environments. This approach could be particularly helpful during in situ uranium bioremediation, when acetate is added to promote the reduction of soluble $\mathrm{U}(\mathrm{VI})$ to insoluble $\mathrm{U}(\mathrm{IV})$ (Anderson et al., 2003; Lovley et al., 1991; N'Guessan et al., 2008) and fine tuning of acetate amendment is necessary to improve the efficiency of the process. As a preliminary step towards implementing this strategy, it was necessary to determine the feasibility of detecting apl genes in Geobacterdominated subsurface environments.

Since the Group I genes are highly conserved among Geobacter species (Fig. 1), degenerate PCR primers 422Fw and $640 \mathrm{Rv}$ were designed based on a sequence alignment of Group I sequences of Geobacter species spanning a particularly well-conserved region of $222 \mathrm{bp}$. This primer pair was tested by successfully amplifying apl fragments using DNA from each Geobacter species available in our culture collection as template (data not shown).
The environmental sample analysed in this study consisted of groundwater collected from a uranium-contaminated aquifer located in Rifle, Colorado, on the 14th day of an acetate-stimulated bioremediation field study (Anderson et al., 2003). Geobacteraceae 16S rRNA gene sequences accounted for $80 \%$ of the microbial community in this sample (Holmes et al., 2007), and six different Geobacter 16S rRNA phylotypes were detected (Fig. 6a). Genomic DNA from this sample was also used to construct an apl clone library with the degenerate primers described above (Fig. 6b). Degenerate primers amplified six unique apl sequences that were all apl Group I homologues closely related to G. uraniireducens and $G$. bemidjiensis. This is significant because these two organisms are members of a clade of Geobacter species that predominate in a diversity of subsurface environments in which dissimilatory metal reduction is an important process (Holmes et al., 2007).

\section{Implications}

The results indicate that Geobacter species contain multiple copies of apl genes, and that, at least in G. sulfurreducens and G. metallireducens, those in the phylogenetic cluster designated Group I are more highly expressed when growth is limited by acetate availability. The presence of multiple copies of putative acetate transporters in the genomes of the Geobacter species suggests not only functional redundancy, but also an adaptation to the nutrient-deprived status that micro-organisms often encounter in their natural environment. Such gene redundancy is common for essential metabolic pathways in this specialized organism (Mahadevan et al., 2006; Segura et al., 2008). Although the role of the putative acetate transporters could not be definitively confirmed with genetic approaches, the finding that the Group I transporters are more highly expressed under acetate-limiting conditions suggests that the expression of these genes may aid in diagnosing the metabolic state of Geobacter species in subsurface environments. Expression of genes related to other metabolic functions such as oxidation of acetate via the tricarboxylic acid cycle (Holmes et al., 2005, 2007), nitrogen fixation (Holmes et al., 2004b) and iron assimilation (O'Neil et al., 2008) by the natural community of Geobacter species that predominates during in situ uranium bioremediation has made it possible to gain insights into rates of metabolism and factors limiting the growth of Geobacter species during bioremediation. The finding that genes highly similar to the Group I transporter genes in Geobacter pure cultures are also present in the Geobacter species that are abundant during in situ uranium bioremediation suggests that monitoring the expression levels of Group I genes in the subsurface may aid the optimization of acetate-mediated bioremediation processes. Preliminary data from field studies indicate that apl genes can be detected in mRNA from environmental samples from Geobacter-dominated field sites undergoing in situ uranium bioremediation, and that there is a correlation between expression levels and 

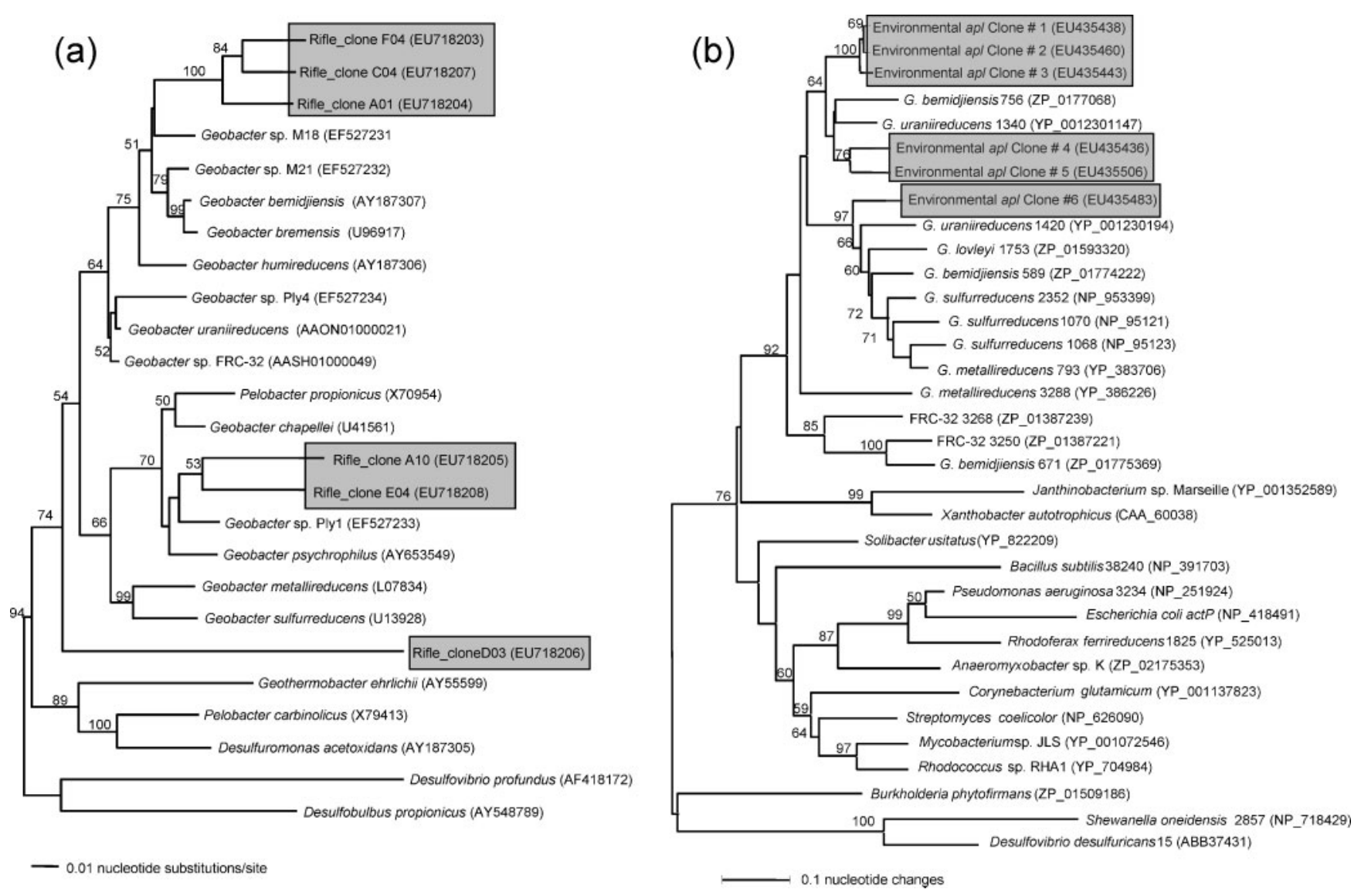

Fig. 6. (a) Phylogenetic tree constructed by maximum-parsimony analysis comparing Geobacter 16S rRNA gene sequences detected in groundwater collected from a uranium-contaminated aquifer in Rifle, Colorado, undergoing bioremediation to $16 \mathrm{~S}$ rRNA gene sequences from other Geobacteraceae isolates. Bootstrap values were obtained from 100 replicates, and Desulfovibrio profundus and Desulfobulbus propionicus were used as outgroups. (b) Analysis of clone library of ap/ genes amplified from the sample described above. Partial sequences corresponding to the $222 \mathrm{bp}$ amplicon from cultured Geobacter and other reference organisms were included for comparison. The phylogenetic tree was inferred from nucleotide acid sequences by neighbour-joining (Saitou \& Nei, 1987), with bootstrap values based on 100 replicates, using MEGA 3 software (Kumar et al., 2004).

acetate availability (H. Elifantz, unpublished results). This information could be used to guide the necessary adjustments to groundwater acetate conditions to ensure that acetate availability is not limiting or, if desired, to restrict acetate inputs to slow down the rate of metal reduction and ensure that $\mathrm{U}(\mathrm{VI})$-reducing Geobacter species remain as dominant components of the subsurface microbial community.

\section{ACKNOWLEDGEMENTS}

This research was supported by the Office of Science (BER), US Department of Energy, ERSP Community Dynamics (Grant no. DEFG02-07ER64377) and Genomes to Life Program, Grant no. DEFC02-02ER63446. We are grateful to our editor, Dr Andrew Holmes, for his valuable contribution and suggestions. We also thank Maddalena Coppi and Pablo Pomposiello for critically reviewing this manuscript.

\section{REFERENCES}

Amos, B. K., Sung, Y., Fletcher, K. E., Gentry, T. J., Wu, W. M., Criddle, C. S., Zhou, J. \& Loffler, F. E. (2007). Detection and quantification of Geobacter lovleyi strain SZ: implications for bioremediation at tetrachloroethene- and uranium-impacted sites. Appl Environ Microbiol 73, 6898-6904.

Anderson, R. T., Vrionis, H. A., Ortiz-Bernad, I., Resch, C. T., Long, P. E., Dayvault, R., Karp, K., Marutzky, S., Metzler, D. R. \& other authors (2003). Stimulated in situ activity of Geobacter species to remove uranium from the groundwater of a uranium-contaminated aquifer. Appl Environ Microbiol 69, 5884-5891.

Caccavo, F., Jr, Lonergan, D. J., Lovley, D. R., Davis, M., Stolz, J. F. \& McInerney, M. J. (1994). Geobacter sulfurreducens sp. nov., a hydrogen- and acetate-oxidizing dissimilatory metal-reducing microorganism. Appl Environ Microbiol 60, 3752-3759.

Coppi, M. V., Leang, C., Sandler, S. J. \& Lovley, D. R. (2001). Development of a genetic system for Geobacter sulfurreducens. Appl Environ Microbiol 67, 3180-3187. 
Cummings, D. E., Snoeyenbos-West, O. L., Newby, D. T., Niggemyer, A. M., Lovley, D. R., Achenbach, L. A. \& Rosenzweig, R. F. (2003). Diversity of Geobacteraceae species inhabiting metal-polluted freshwater lake sediments ascertained by $16 \mathrm{~S}$ rDNA analyses. Microb Ecol 46, 257-269.

Didonato, R. J., Jr, Postier, B., Nevin, K., Xu, B., Liu, A. \& Lovley, D. R. (2006). Microarray analysis of donor-limited and acceptorlimited Geobacter metallireducens. In 106th General ASM Meeting, Orlando, FL, K-109.

Eden, P. A., Schmidt, T. M., Blakemore, R. P. \& Pace, N. R. (1991) Phylogenetic analysis of Aquaspirillum magnetotacticum using polymerase chain reaction-amplified $16 \mathrm{~S}$ rRNA-specific DNA. Int J Syst Bacteriol 41, 324-325.

Esteve-Nuñez, A., Rothermich, M., Sharma, M. \& Lovley, D. R. (2005). Growth of Geobacter sulfurreducens under nutrient-limiting conditions in continuous culture. Environ Microbiol 7, 641-648.

Finneran, K. T., Housewright, M. E. \& Lovley, D. R. (2002). Multiple influences of nitrate on uranium solubility during bioremediation of uranium-contaminated subsurface sediments. Environ Microbiol 4, 510-516.

Gimenez, R., Nunez, M. F., Badia, J., Aguilar, J. \& Baldoma, L. (2003). The gene $y j c G$, cotranscribed with the gene acs, encodes an acetate permease in Escherichia coli. J Bacteriol 185, 6448-6455.

Haveman, S. A., Holmes, D. E., Ding, Y. H., Ward, J. E., Didonato, R. J., Jr \& Lovley, D. R. (2006). c-Type cytochromes in Pelobacter carbinolicus. Appl Environ Microbiol 72, 6980-6985.

Holmes, D. E., Finneran, K. T., O'Neil, R. A. \& Lovley, D. R. (2002). Enrichment of members of the family Geobacteraceae associated with stimulation of dissimilatory metal reduction in uranium-contaminated aquifer sediments. Appl Environ Microbiol 68, 2300-2306.

Holmes, D. E., Nevin, K. P. \& Lovley, D. R. (2004a). Comparison of 16s $r R N A$, nifD, $r e c A, g y r B, r p o B$, and fusA genes within the family Geobacteraceae fam. nov. Int J Syst Evol Microbiol 54, 1591-1599.

Holmes, D. E., Nevin, K. P. \& Lovley, D. R. (2004b). In situ expression of nifD in Geobacteraceae in subsurface sediments. Appl Environ Microbiol 70, 7251-7259.

Holmes, D. E., Nevin, K. P., O'Neil, R. A., Ward, J. E., Adams, L. A., Woodard, T. L., Vrionis, H. A. \& Lovley, D. R. (2005). Potential for quantifying expression of the Geobacteraceae citrate synthase gene to assess the activity of Geobacteraceae in the subsurface and on currentharvesting electrodes. Appl Environ Microbiol 71, 6870-6877.

Holmes, D. E., O'Neil, R. A., Vrionis, H. A., N'guessan, L. A., OrtizBernad, I., Larrahondo, M. J., Adams, L. A., Ward, J. A., Nicoll, J. S. \& other authors (2007). Subsurface clade of Geobacteraceae that predominates in a diversity of $\mathrm{Fe}(\mathrm{III})$-reducing subsurface environments. ISME J 1, 663-677.

Istok, J. D., Senko, J. M., Krumholz, L. R., Watson, D., Bogle, M. A. Peacock, A., Chang, Y. J. \& White, D. C. (2004). In situ bioreduction of technetium and uranium in a nitrate-contaminated aquifer. Environ Sci Technol 38, 468-475.

Kim, B. C., Qian, X., Leang, C., Coppi, M. V. \& Lovley, D. R. (2006). Two putative $c$-type multiheme cytochromes required for the expression of $\mathrm{OmcB}$, an outer membrane protein essential for optimal $\mathrm{Fe}(\mathrm{III})$ reduction in Geobacter sulfurreducens. J Bacteriol $\mathbf{1 8 8}$, 3138-3142.

Kovach, M. E., Elzer, P. H., Hill, D. S., Robertson, G. T., Farris, M. A., Roop, R. M., II \& Peterson, K. M. (1995). Four new derivatives of the broad-host-range cloning vector pBBR1MCS, carrying different antibiotic-resistance cassettes. Gene 166, 175-176.

Kumar, S., Tamura, K. \& Nei, M. (2004). MEGA3: integrated software for Molecular Evolutionary Genetics Analysis and sequence alignment. Brief Bioinform 5, 150-163.
Lane, D. J., Pace, B., Olsen, G. J., Stahl, D. A., Sogin, M. L. \& Pace, N. R. (1985). Rapid determination of $16 \mathrm{~S}$ ribosomal RNA sequences for phylogenetic analyses. Proc Natl Acad Sci U S A 82, 6955-6959.

Leang, C., Coppi, M. V. \& Lovley, D. R. (2003). OmcB, a $c$-type polyheme cytochrome, involved in Fe(III) reduction in Geobacter sulfurreducens. J Bacteriol 185, 2096-2103.

Livak, K. J. \& Schmittgen, T. D. (2001). Analysis of relative gene expression data using real-time quantitative PCR and the $2^{-\Delta \Delta C t}$ method. Methods 25, 402-408.

Lloyd, J. R., Leang, C., Hodges Myerson, A. L., Coppi, M. V., Cuifo, S., Methe, B., Sandler, S. J. \& Lovley, D. R. (2003). Biochemical and genetic characterization of PpcA, a periplasmic c-type cytochrome in Geobacter sulfurreducens. Biochem J 369, 153-161.

Lovley, D. R. (2003). Cleaning up with genomics: applying microbiology to bioremediation. Nat Rev Microbiol 1, 35-44.

Lovley, D. R. \& Phillips, E. J. P. (1986). Organic matter mineralization with the reduction of ferric iron in anaerobic sediments. Appl Environ Microbiol 51, 683-689.

Lovley, D. R. \& Phillips, E. J. P. (1988). Novel mode of microbial energy metabolism: organic carbon oxidation coupled to dissimilatory reduction of iron or manganese. Appl Environ Microbiol 54, 1472-1480.

Lovley, D. R., Phillips, E. J. P., Gorby, Y. A. \& Landa, E. R. (1991). Microbial reduction of uranium. Nature 350, 413-416.

Lovley, D. R., Phillips, E. J., Lonergan, D. J. \& Widman, P. K. (1995). $\mathrm{Fe}(\mathrm{III})$ and S0 reduction by Pelobacter carbinolicus. Appl Environ Microbiol 61, 2132-2138.

Lovley, D. R., Mahadevan, R. \& Nevin, K. (2008). Systems biology approach to bioremediation with extracellular electron transfer. In Microbial Biodegradation: Genomics and Molecular Biology, pp. 71-96. Edited by E. Diaz. Norwich, UK: Horizon Scientific Press.

Luo, W., Wu, W. M., Yan, T., Criddle, C. S., Jardine, P. M., Zhou, J. \& Gu, B. (2007). Influence of bicarbonate, sulfate, and electron donors on biological reduction of uranium and microbial community composition. Appl Microbiol Biotechnol 77, 713-721.

Mahadevan, R., Bond, D. R., Butler, J. E., Esteve-Nuñez, A., Coppi, M. V., Palsson, B. O., Schilling, C. H. \& Lovley, D. R. (2006). Characterization of metabolism in the $\mathrm{Fe}$ (III)-reducing organism Geobacter sulfurreducens by constraint-based modeling. Appl Environ Microbiol 72, 1558-1568.

Mehta, T., Childers, S. E., Glaven, R., Lovley, D. R. \& Mester, T. (2006). A putative multicopper protein secreted by an atypical type II secretion system involved in the reduction of insoluble electron acceptors in Geobacter sulfurreducens. Microbiology 152, 2257-2264.

Methé, B. A., Nelson, K. E., Eisen, J. A., Paulsen, I. T., Nelson, W., Heidelberg, J. F., Wu, D., Wu, M., Ward, N. \& other authors (2003). Genome of Geobacter sulfurreducens: metal reduction in subsurface environments. Science 302, 1967-1969.

N'Guessan, A. L., Vrionis, H. A., Resch, C. T., Long, P. E. \& Lovley, D. R. (2008). Sustained removal of uranium from contaminated groundwater following stimulation of dissimilatory metal reduction. Environ Sci Technol 42, 2999-3004.

North, N. N., Dollhopf, S. L., Petrie, L., Istok, J. D., Balkwill, D. L. \& Kostka, J. E. (2004). Change in bacterial community structure during in situ biostimulation of subsurface sediment cocontaminated with uranium and nitrate. Appl Environ Microbiol 70, 4911-4920.

Oh, M. K., Rohlin, L., Kao, K. C. \& Liao, J. C. (2002). Global expression profiling of acetate-grown Escherichia coli. J Biol Chem 277, 1317513183.

O'Neil, R. A., Holmes, D. E., Coppi, M. V., Adams, L. A., Larrahondo, M. J., Ward, J. E., Nevin, K. P., Woodard, T. L., Vrionis, H. A. \& other 
authors (2008). Gene transcript analysis of assimilatory iron limitation in Geobacteraceae during groundwater bioremediation. Environ Microbiol 10, 1218-1230.

Petrie, L., North, N. N., Dollhopf, S. L., Balkwill, D. L. \& Kostka, J. E. (2003). Enumeration and characterization of iron(III)-reducing microbial communities from acidic subsurface sediments contaminated with uranium(VI). Appl Environ Microbiol 69, 7467-7479.

Risso, C., Van Dien, S. J., Orloff, A., Lovley, D. R. \& Coppi, M. V. (2008). Elucidation of an alternate isoleucine biosynthesis pathway in Geobacter sulfurreducens. J Bacteriol 190, 2266-2274.

Rozen, S. \& Skaletsky, H. (2000). Primer3 on the WWW for general users and for biologist programmers. Methods Mol Biol 132, 365-386.

Saitou, N. \& Nei, M. (1987). The neighbor-joining method: a new method for reconstructing phylogenetic trees. Mol Biol Evol 4, 406-425.

Sanford, R. A., Wu, Q., Sung, Y., Thomas, S. H., Amos, B. K., Prince, E. K. \& Loffler, F. E. (2007). Hexavalent uranium supports growth of Anaeromyxobacter dehalogenans and Geobacter spp. with lower than predicted biomass yields. Environ Microbiol 9, 2885-2893.

Schink, B. (1984). Fermentation of 2,3-butanediol by Pelobacter carbinolicus sp. nov. and Pelobacter propionicus sp. nov., and evidence for propionate formation from $\mathrm{C}_{2}$ compounds. Arch Microbiol 137, $33-41$.

Schloss, P. D. \& Handelsman, J. (2005). Introducing DOTUR, a computer program for defining operational taxonomic units and estimating species richness. Appl Environ Microbiol 71, 1501-1506.
Segura, D., Mahadevan, R., Juarez, K. \& Lovley, D. R. (2008). Computational and experimental analysis of redundancy in the central metabolism of Geobacter sulfurreducens. PLOS Comput Biol 4, e36.

Smith, P. K., Krohn, R. I., Hermanson, G. T., Mallia, A. K., Gartner, F. H., Provenzano, M. D., Fujimoto, E. K., Goeke, N. M., Olson, B. J. \& Klenk, D. C. (1985). Measurement of protein using bicinchoninic acid. Anal Biochem 150, 76-85.

Swofford, D. L. (1998). PAUP ${ }^{*}$ : Phylogenetic analysis using parsimony ( ${ }^{\star}$ and other methods), version 4. Sunderland, MA: Sinauer Associates.

Thompson, J. D., Gibson, T. J., Plewniak, F., Jeanmougin, F. \& Higgins, D. G. (1997). The CLUSTAL_X Windows interface: flexible strategies for multiple sequence alignment aided by quality analysis tools. Nucleic Acids Res 25, 4876-4882.

Vrionis, H. A., Anderson, R. T., Ortiz-Bernad, I., O’Neill, K. R., Resch, C. T., Peacock, A. D., Dayvault, R., White, D. C., Long, P. E. \& Lovley, D. R. (2005). Microbiological and geochemical heterogeneity in an in situ uranium bioremediation field site. Appl Environ Microbiol 71, 6308-6318.

Yan, B., Methe, B. A., Lovley, D. R. \& Krushkal, J. (2004). Computational prediction of conserved operons and phylogenetic footprinting of transcription regulatory elements in the metalreducing bacterial family Geobacteraceae. J Theor Biol 230, 133-144.

Edited by: A. Holmes 